\title{
Application of Rapid Sample Preparation Method and Monitoring for Cholesterol Content in Chicken Egg and Egg powder
}

\author{
Jung-Min Park, In-Seek Jeong ${ }^{1}$, Byung-Man Kwak', Jang-Hyuk Ahn¹, Donggil Leem², \\ Jayoung Jeong ${ }^{2}$, and Jin-Man Kim* \\ Department of Food Science and Biotechnology of Animal Resources, Konkuk University, Seoul 143-701, Korea \\ ${ }^{1}$ Food Safety Center, Research and Development Institute, Namyang Dairy Co., Ltd., Gongju 314-914, Korea \\ ${ }^{2}$ Nutrition and Functional Food Research Team, Korea Food and Drug Administration, Chungwon 363-951, Korea
}

\begin{abstract}
The aim of this study was to develop sample preparation method and evaluate the exact cholesterol content in egg and egg powder purchased from Korean markets, and to determine whether significant differences exist among various egg products, since a variety of products are available in Korean markets and there are no recent databases for cholesterol. To evaluate the cholesterol content in chicken egg sold in Korean local market, a simple method using non-heated saponification to determine cholesterol for emulsified foods was applied. The results of recovery for egg and egg powder were in a range of 92.4-105.0\%, with a relative standard deviation between $1.1 \%$ and $2.8 \%$ by using gas chromatography-flame ionization detector. Therefore, the total cholesterol content in whole egg was estimated between 160.8 and $226.3 \mathrm{mg} / \mathrm{egg}$ (AV(average) $186.8 \pm 3.5)$, which is similar or lower than previously reported levels. The value for cholesterol in egg powder was estimated between 2.94 and $3.49 \mathrm{mg} / \mathrm{g}$ (AV 3.23 \pm 0.15 ). We suggested method that can be applicable to chicken egg and egg powder matrix as providing rapid and accurate determination of cholesterol in egg and egg powder. This information will be helpful for processed food producers for deciding food labels of cholesterol content.
\end{abstract}

Key words: egg, egg powder, cholesterol, non-heated saponification, gas chromatography

\section{Introduction}

Cholesterol is present in significant amounts in most animal-derived foods such as meat, fish, egg, milk, and milk products. Cholesterol levels have been thoroughly examined by research institutes such as the United States Department of Agriculture (United States Department of Agriculture, 2011) and the Korean Nutrition Society (Kang, 2009) to provide nutritional information to consumers and for precise food labeling by food producers.

Official analytical methods for determining the cholesterol content in food products have been published by the Association of Official Analytical Chemists (AOAC) and International Dairy Federation (IDF). The AOAC method is applicable for multicomponent foods and general foods (Horwitz, 2011a; Horwitz, 2011b), and method in Korea Food Code (2012) was adopted by Korea Food and Drug

*Corresponding author: Jin-Man Kim, Department of Food Science and Biotechnology of Animal Resources, Konkuk University, Seoul 143-701, Korea. Tel: 82-2-450-3688, Fax: 82-2455-1044, E-mail: jinmkim@konkuk.ac.kr
Administration (KFDA), cited by the AOAC 994.10 method. The IDF method is an accurate and precise method for measuring cholesterol in milk and milk products (International Dairy Federation, 2006). However, these methods cannot be used to determine cholesterol levels in eggs and egg powder without performing an additional solvent extraction step (International Dairy Federation, 2001). Moreover, sample preparation is a time-consuming process. Cholesterol is a non-saponifiable material that is present in small amounts relative to the total lipid content in eggs. Since lipids in eggs act as an interfering material during chromatographic separation, saponification by potassium hydroxide $(\mathrm{KOH})$ is generally used for lipid extraction (Beyer and Jensen, 1989; Hurst et al., 1985; Sweeney and WeBirauch, 1976). During pretreatment, $\mathrm{KOH}$ is used to hydrolyze acylglycerides to glycerol and fatty acids so that hydrolyzed materials can be removed by washing with water; thus, residual matter such as cholesterol remains in the extracted solution layer, and the solution can be subjected to chromatographic separation. However, the official sample preparation process is both time consuming and 
labor intensive; thus, a rapid method was developed for sample preparation (Jeong et al., 2012).

The first aim of this study was to carry out the precise determination of cholesterol content in eggs and processed egg powder by gas chromatography using a flame ionization detector (GC-FID) following direct saponification without heating. Our second aim was to evaluate the exact cholesterol content in eggs and egg powder to determine whether significant differences exist among various egg products, since a variety of products are available in Korean markets and there are no recent databases for cholesterol.

\section{Materials and Methods}

\section{Chemicals}

Each 10 egg and egg powder samples were purchased from a local market as well as from a manufacturer and stored at $4^{\circ} \mathrm{C}$. Certified reference material, fatty acids and cholesterol in a frozen diet composite (Standard Reference Material [SRM] 1544), was purchased from the National Institute for Standard and Technology (NIST; USA) and used for method validation. The cholesterol content of SRM 1544 was $14.83 \pm 0.94 / 100 \mathrm{~g}$. KOH and $28 \%$ ammonia solution were purchased from Junsei Chemical (Japan). Reagent-grade anhydrous magnesium sulfate $\left(\mathrm{MgSO}_{4}\right)$ in a powdered form and diethyl ether for extraction were purchased from Thermo Fisher Scientific (USA). Methanol and ethanol were purchased from Burdick and Jackson (USA). Ultrapure water (18.0 ohm) obtained using the Barnstead Diamond TII system (USA) was used in all experiments.

\section{Instruments and experimental conditions}

An Agilent model 6890 gas chromatograph instrument equipped with a $30 \mathrm{~m} \times 0.25 \mathrm{~mm}, 0.25 \mu \mathrm{m}) \mathrm{HP}-5$ capillary column (Agilent, USA) and an FID was used to separate and detect cholesterol. A running time of $38 \mathrm{~min}$ was used for each sample solution to prevent overlapping of cholesterol and $\alpha$-tocopherol peaks (Kim et al., 2011). The following instrumental conditions were employed for GC-FID analysis: injection volume of $1 \mu \mathrm{L}$ and $1.0 \mathrm{~mL} /$ min flow rate of nitrogen carrier gas at a split ratio of 10:1 with constant flow control. The injector and detector temperatures used were $280^{\circ} \mathrm{C}$ and $290^{\circ} \mathrm{C}$, respectively. The initial oven temperature was maintained at $250^{\circ} \mathrm{C}$ for $25 \mathrm{~min}$ and then gradually increased to $290^{\circ} \mathrm{C}$ at a rate of $10^{\circ} \mathrm{C} / \mathrm{min}$, after which it was maintained at $290^{\circ} \mathrm{C}$ for 9 $\min$.

\section{Standard and sample preparations}

A stock standard solution of $1,000 \mu \mathrm{g} / \mathrm{mL}$ cholesterol in diethyl ether was prepared from an SRM 911c cholesterol standard (NIST, USA; assayed at 99.2\% $\pm 0.4 \%$ ). $5 \alpha$ Cholestane (Sigma-Aldrich, USA; 99.91\% purity) was used as an internal standard (IS), and it was prepared as a stock and working standard solution at a concentration of $1,000 \mu \mathrm{g} / \mathrm{mL}$ in diethyl ether. A previously published sample preparation method for measuring cholesterol (Jeong et al., 2012) was applied to the egg and powdered egg products. For extraction, a whole egg was used after weighing the white and yolk partitions in a $50 \mathrm{~mL}$ polypropylene centrifuge tube. $0.2 \mathrm{~g}$ of egg or egg powder samples was added to $5 \mathrm{~mL}$ distilled water, and then, $1 \mathrm{~mL}$ of $28 \%$ ammonia solution was added, and the tube was placed in a water bath until the sample was dissolved. Four mL of ethanol and $10 \mathrm{~mL}$ of IS stock solution were added for cholesterol extraction, and the sample was covered and vigorously stirred for $1 \mathrm{~min}$ on a vortex mixer. After mixing, $4 \mathrm{~g}$ of anhydrous $\mathrm{MgSO}_{4}$ was added, and the sample was immediately mixed for $1 \mathrm{~min}$ on a vortex mixer. The sample was centrifuged at 4,000 rpm for $5 \mathrm{~min}$ at $4^{\circ} \mathrm{C}$. For saponification without heating, a 4$\mathrm{mL}$ aliquot of the upper layer was added to $0.2 \mathrm{~mL}$ of $2 \mathrm{M}$ $\mathrm{KOH}$ in methanol. This sample was mixed vigorously for $1 \mathrm{~min}$ on a vortex mixer. After incubating for $5 \mathrm{~min}$ at room temperature, the sample was centrifuged at 4,000 rpm for $5 \mathrm{~min}$ at $4^{\circ} \mathrm{C}$. An aliquot of the upper layer was transferred into an autosampler vial for GC-FID analysis.

\section{Method validation}

The extraction method was validated by 3 examiners on the basis of the AOAC guidelines for single laboratory validation of chemical methods (AOAC International, 2002a; AOAC International, 2002b). Parameters such as linearity, limit of detection (LOD), limit of quantification (LOQ), method detection limit (MDL), and recovery was tested to validate the method and its application to egg and egg powder products. Linearity was characterized on the basis of the average coefficient of determination $\left(r^{2}\right)$ and calculated using a 5-point standard curve. The cholesterol standard ( $\sim 0.1 \mathrm{~g})$ was weighed and dissolved in $100 \mathrm{~mL}$ of ethyl ether. The appropriate amounts of cholesterol standard solution were diluted to obtain the following concentrations: 10, 100, 200, 500, and 1,000 $\mu \mathrm{g} /$ $\mathrm{mL}$, which were used as standard working solutions. LOD and LOQ were determined by diluting the cholesterol standard working solutions to obtain signal/noise ratios of approximately 3:1 for LOD and approximately 10:1 for 
LOQ. MDL was determined by multiplying LOD solvent quantities $(\mathrm{mL})$ and dividing this value by sample amounts (g). Recovery was evaluated using SRM 1544 and a cholesterol-spiking material test in egg and egg powder matrices. The accuracy of the method for estimating cholesterol content of egg and egg powder samples was evaluated using a certification sheet based on the cholesterol values of SRM 1544. Samples were added to $1 \mathrm{~mL}$ of standard solution prepared at a concentration of $100 \mathrm{mg} /$ $100 \mathrm{~g}$ and analyzed quantitatively; the results were compared to samples not containing the standard solution. Recovery was then calculated using the following equation:

$(\mathrm{A} 1-\mathrm{A} 2) / \mathrm{A} 3 \times 100$, where $\mathrm{A} 1$ is the result obtained when the cholesterol standard solution was used, A2 is the result obtained when the standard solution was not used, and A3 is the amount of cholesterol standard solution used.

\section{Results and Discussion}

\section{Microextraction and non-heated saponification pro- cess}

According to a rapid microextraction method (Jeong et al., 2012), $10 \mathrm{~mL}$ of diethyl ether was considered to be an optimum solvent for cholesterol extract. Additionally, $4.0 \mathrm{~g}$ of $\mathrm{MgSO}_{4}$ was added to transfer salts into the organic phase, and $2 \mathrm{M} \mathrm{KOH}$ in methanol was used as the nonheated saponification solution (Jeong et al., 2012). Application of a previously developed method for measuring cholesterol content in eggs and egg powder was examined in this study. The optimum sample weight to be used for eggs and egg powder was a critical factor to be considered in this study. In previous studies, the cholesterol content in the edible portion of eggs was estimated to be $392 \mathrm{mg} / 100 \mathrm{~g}$, or in the range of $120-193 \mathrm{mg}$ per egg (weight of 1 egg is 50-70 g) (Guardiola et al., 1994; Naviglio et al., 2012). Thus, the optimal sample amount for using this method was $0.2 \mathrm{~g}$ for egg or egg powder samples. This sampling amount corresponds to a cholesterol concentration of approximately 300-500 parts per million (ppm), which is within the range of detection for the cholesterol calibration curve (10-1,000 ppm). Except for the amount of egg used, other experimental conditions did not differ from those used in our previous study for examining emulsified foods (Jeong et al., 2012). Comparison among the method of AOAC, KFDA and the applied method is shown in Fig. 1.

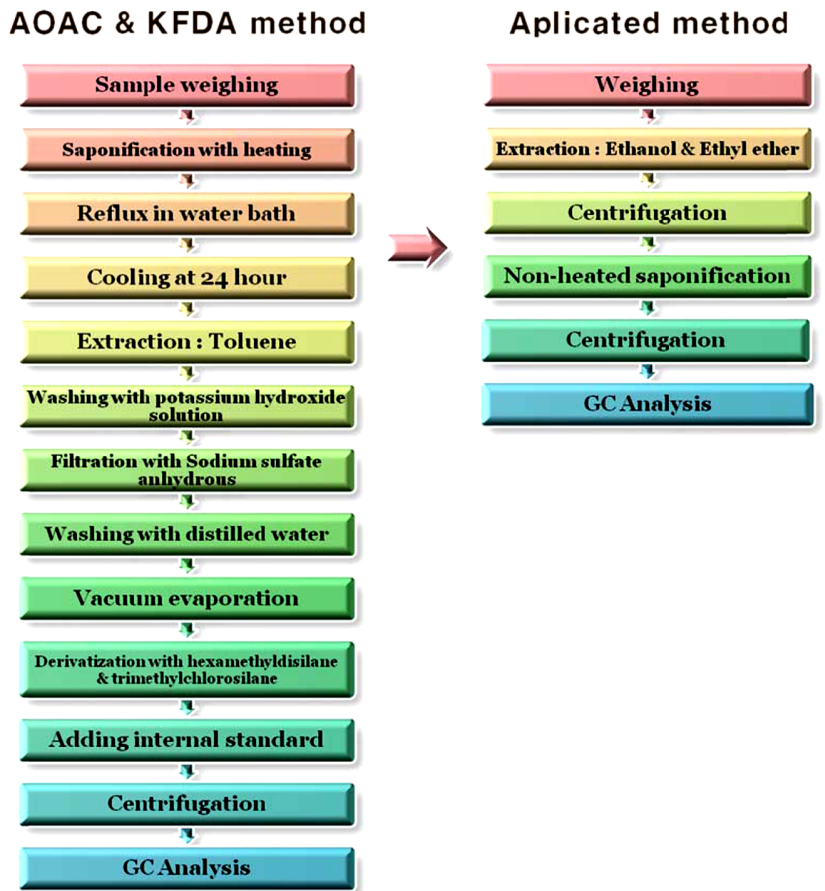

Fig. 1. Comparison of the steps required for the determination of cholesterol in egg and egg powder using the Association of Official Agricultural Chemists (AOAC) method, Korea Food and Drug Administration (KFDA) method, and the applied method.

\section{Instrumental analysis}

GC-FID chromatograms for egg yolk and egg powder are shown in Fig. 2. Cholesterol in the test solution containing egg yolk was successfully separated over a retention time (RT) of $27.48 \mathrm{~min}$ and that from egg powder was separated with an RT of $27.44 \mathrm{~min}$. Chromatograms for the 2 types of test samples were similar, and the RT for $5 \alpha$-cholestane was $16.43 \mathrm{~min}$.

\section{Validation and recovery test}

Method validation reports are summarized in Table 1. Linearity of detecting cholesterol by FID was determined from the calibration plots, which were constructed over a concentration range of 10-1000 $\mu \mathrm{g} / \mathrm{mL}$. Least-squares linear regression analysis of the data showed high values of coefficient-of-determination $\left(r^{2}\right)$ values $\left(r^{2}>0.9999\right)$. LOD and LOQ values were $3.38 \mathrm{mg} / \mathrm{kg}$ and $11.27 \mathrm{mg} / \mathrm{kg}$, respectively. The MDL value was $1.69 \mathrm{mg} / \mathrm{kg}$ for egg and egg powder samples. Analytical results of the recovery test were satisfactory, and cholesterol concentrations were in the range of certified values for CRMs (NIST SRM 1544). Recovery in the spiking test for egg and egg powder was $105.0 \%$ and $92.4 \%$, with a relative standard deviation (RSD) of $2.8 \%$ and $1.1 \%$, respectively. Thus, the 


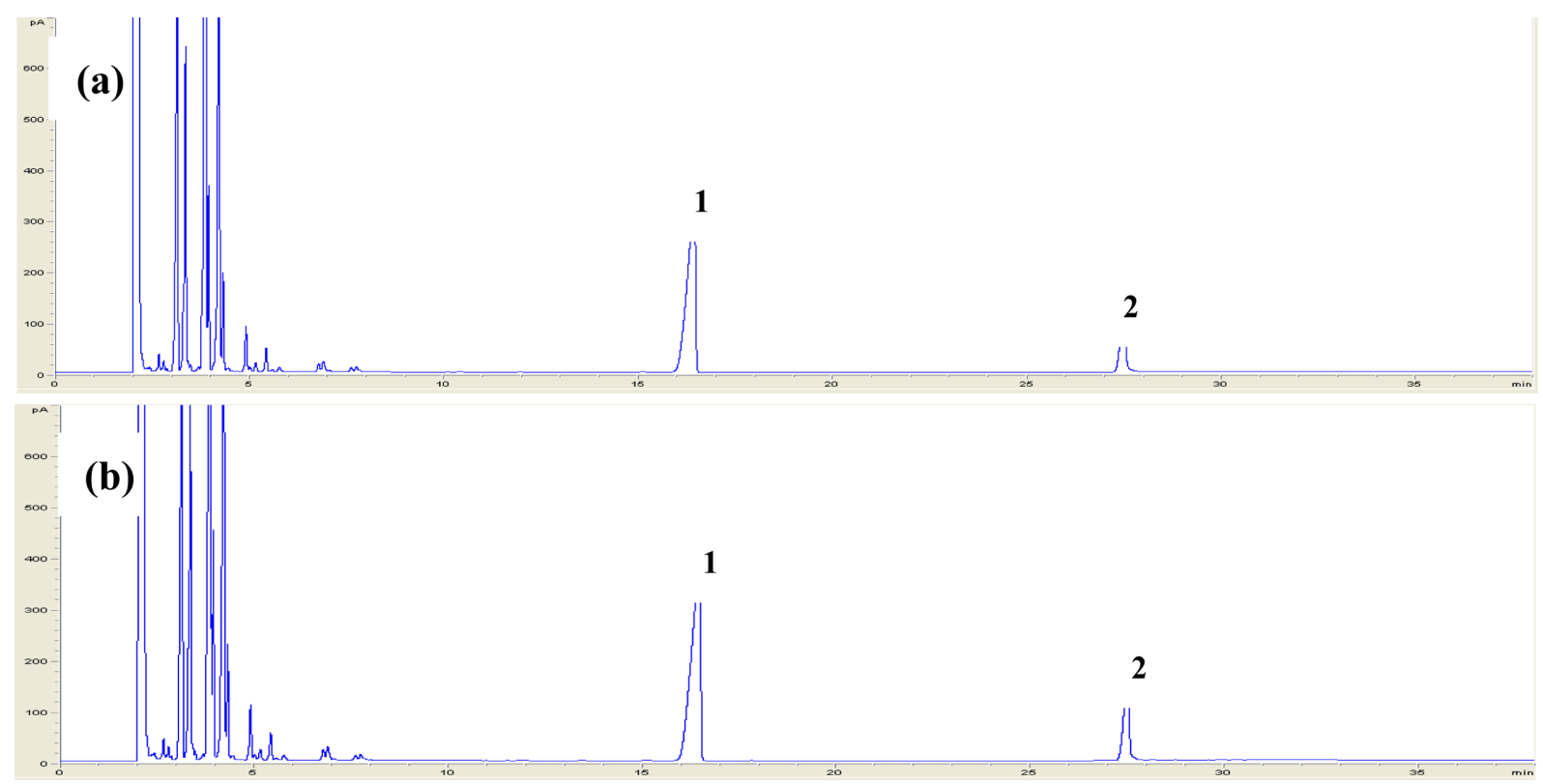

Fig. 2. GC-FID Chromatograms of egg yolk and egg powder for measuring cholesterol contents under optimized conditions. (a); egg yolk, (b); egg powder, 1; 5 $\alpha$-cholestane, 2 : cholesterol.

Table 1. Validation information for the cholesterol content in eggs and egg powders using non-heated saponification method for GC-FID analysis

\begin{tabular}{|c|c|c|c|c|c|c|}
\hline Sample & $r^{2}$ & $\mathrm{LOD}^{\mathrm{l})}(\mathrm{mg} / \mathrm{kg})$ & $\mathrm{LOQ}^{2)}(\mathrm{mg} / \mathrm{kg})$ & $\mathrm{MDL}^{3)}(\mathrm{mg} / \mathrm{kg})$ & Recovery $^{4)}(\%)$ & $\mathrm{RSD}^{5)}(\%)$ \\
\hline Egg & \multirow{2}{*}{0.9999} & \multirow{2}{*}{3.38} & \multirow{2}{*}{11.27} & \multirow{2}{*}{1.69} & $92.41 \pm 2.55$ & 2.76 \\
\hline Egg powder & & & & & $105.01 \pm 1.12$ & 1.07 \\
\hline $\begin{array}{c}\text { Certified Reference } \\
\text { Material }\end{array}$ & \multicolumn{2}{|c|}{$\begin{array}{c}\text { SRM 15446) } \\
\text { Tested value }{ }^{7)}(\mathrm{mg} / 100 \mathrm{~g})\end{array}$} & \multicolumn{2}{|c|}{ RSD (\%) } & & \\
\hline & & 0.16 & \multicolumn{2}{|c|}{1.10} & & \\
\hline
\end{tabular}

${ }^{1)} \mathrm{LOD}:$ limit of detection. $\mathrm{S} / \mathrm{N}=3$.

${ }^{2)} \mathrm{LOQ}$ : limit of quantitation. $\mathrm{S} / \mathrm{N}=10$.

${ }^{3)} \mathrm{MDL}$ : method detection limit.

${ }^{4)}$ Spiking levels of samples were $100 \mathrm{mg} / 100 \mathrm{~g}$.

${ }^{5)} \mathrm{RSD}$ : relative standard deviation.

${ }^{6}$ Certified value of SRM 1544 is $14.83 \pm 0.94 \mathrm{mg} / 100 \mathrm{~g}$.

${ }^{7)}$ Values are mean \pm S.D of 3 replicates.

developed method is accurate and precise for examining egg and egg powder samples.

\section{Monitoring test for cholesterol concentration in egg and egg powder samples}

Thirty egg samples from 10 companies and 30 egg powder samples from 5 companies were tested using AOAC 994.10 method and non-heated saponification method. Sample pretreatments were repeated thrice for each sample, and the weight of egg yolks and whole eggs was estimated. Tested values for eggs are shown in Table 2 . Weights of egg yolk were estimated to be in the range of 13.82-18.30 g (average value: $15.94 \mathrm{~g}, 8.76 \% \mathrm{RSD}$ ) and cholesterol contents were in the range of $10.53-12.95 \mathrm{mg} /$ g (average value: $11.72 \mathrm{mg} / \mathrm{g}, 5.69 \% \mathrm{RSD}$ ). No significant difference was observed between AOAC method and new method in the in cholesterol content among egg yolks, indicating that cholesterol levels are similar in various egg yolks through the statistical analysis by ANOVA (Oneway Analysis Of Variance) $(p<0.05)$. Egg yolk weight and cholesterol levels was determined using the whole egg. Tested values for egg powders are shown in Table 3. Processed egg powder contained slightly higher cholesterol quantities than raw eggs. The cholesterol content of whole egg powder was one-fourth of that in egg yolk powder, which was nearly the same as the weight ratio of egg yolk and whole egg in raw material.

In this study, cholesterol levels in eggs and egg powder sold in Korean markets were found to be similar or lower than those previously reported in Europe as the range of 
Table 2. Tested cholesterol values for whole egg using AOAC 994.10 method and non-heated saponification method for GC-FID analysis

\begin{tabular}{|c|c|c|c|c|c|c|c|c|c|c|c|}
\hline \multirow{2}{*}{\multicolumn{2}{|c|}{ Samples }} & \multirow[b]{2}{*}{$\begin{array}{l}\text { Weight of } \\
\text { egg yolk } \\
\text { (g) }\end{array}$} & \multicolumn{2}{|c|}{ AOAC method } & \multicolumn{2}{|c|}{ New method } & \multirow[b]{2}{*}{$\begin{array}{l}\text { Weight of } \\
\text { whole egg } \\
\text { (g) }\end{array}$} & \multicolumn{2}{|c|}{ AOAC method } & \multicolumn{2}{|c|}{ New method } \\
\hline & & & $\begin{array}{c}\text { Egg yolk } \\
\text { Tested value }{ }^{1)} \\
(\mathrm{mg} / \mathrm{g})\end{array}$ & $\begin{array}{c}\text { RSD } \\
(\%)\end{array}$ & $\begin{array}{c}\text { Egg yolk } \\
\text { Tested value } \\
(\mathrm{mg} / \mathrm{g})\end{array}$ & $\begin{array}{c}\text { RSD } \\
(\%)\end{array}$ & & $\begin{array}{c}\text { Whole egg } \\
\text { Tested value } \\
\text { (mg/egg) }\end{array}$ & $\begin{array}{c}\text { RSD } \\
(\%)\end{array}$ & $\begin{array}{c}\text { Whole egg } \\
\text { Tested value } \\
\text { (mg/egg) }\end{array}$ & $\begin{array}{l}\text { RSD } \\
(\%)\end{array}$ \\
\hline \multirow{10}{*}{ Egg } & S-1 & 14.79 & $12.43 \pm 0.72$ & 3.82 & $12.95 \pm 0.14$ & 1.06 & 64.00 & $183.23 \pm 5.43$ & 2.87 & $191.52 \pm 8.08$ & 3.22 \\
\hline & $S-2$ & 15.51 & $12.12 \pm 0.33$ & 2.36 & $11.69 \pm 0.11$ & 0.96 & 6344 & $193.24 \pm 2.23$ & 2.42 & $181.28 \pm 1.91$ & 1.05 \\
\hline & $S-3$ & & $11.10 \pm 0.24$ & & $11.59 \pm 0$ & & & $193.73 \pm 2.34$ & 1.89 & $191.63 \pm$ & 0.69 \\
\hline & S-4 & 13.82 & $12.43 \pm 0.15$ & 2.22 & $11.63 \pm 0.10$ & 0.83 & 3.17 & $162.23 \pm 3.45$ & 3.48 & $160.76 \pm 4.06$ & 2.53 \\
\hline & $S-5$ & & $12.18 \pm 0.37$ & 2.15 & $11.51 \pm 0.06$ & 0.56 & 62.97 & $176.76 \pm 4.33$ & 2.34 & $182.45 \pm 3.20$ & 1.76 \\
\hline & S-6 & & $11.24 \pm 0.69$ & 3.83 & $12.08 \pm 0.12$ & 1.00 & & $188.55 \pm 6.73$ & 2.22 & $191.14 \pm 5.81$ & 3.04 \\
\hline & S-7 & 15.22 & $11.03 \pm 0.23$ & 1.83 & $10.53 \pm 0.10$ & 0.99 & 56.25 & $167.83 \pm 6.53$ & 2.84 & $160.34 \pm 1.65$ & 1.03 \\
\hline & $\mathrm{S}-8$ & & $11.48 \pm 0.46$ & 1.36 & $11.37 \pm 0.10$ & 0.90 & 65.03 & $210.23 \pm 2.35$ & 2.24 & $208.00 \pm 2.14$ & 1.03 \\
\hline & S-9 & 18.12 & $12.28 \pm 0.73$ & 3.63 & $12.49 \pm 0.13$ & 1.06 & 60.89 & $218.26 \pm 2.36$ & 2.44 & $226.33 \pm 2.42$ & 1.07 \\
\hline & S-10 & 15.39 & $11.84 \pm 0.39$ & 2.15 & $11.32 \pm 0.07$ & 0.65 & 61.59 & $182.53 \pm 3.77$ & 1.89 & $174.17 \pm 6.09$ & 3.50 \\
\hline
\end{tabular}

${ }^{1)}$ Values are mean \pm S.D of 3 replicates.

Table 3. Tested cholesterol values for egg powder using AOAC 994.10 method and non-heated saponification method for GC-FID analysis

\begin{tabular}{|c|c|c|c|c|c|c|c|c|c|}
\hline \multirow{3}{*}{\multicolumn{2}{|c|}{ Samples }} & \multicolumn{4}{|c|}{ AOAC method } & \multicolumn{4}{|c|}{ New method } \\
\hline & & \multirow{2}{*}{$\begin{array}{c}\text { Egg yolk } \\
\text { Tested value }{ }^{1)} \\
(\mathrm{mg} / \mathrm{g})\end{array}$} & \multirow{2}{*}{\multicolumn{2}{|c|}{$\begin{array}{c}\text { Whole egg } \\
\text { Tested value }{ }^{1)} \\
(\mathrm{mg} / \mathrm{g})\end{array}$}} & \multirow[b]{2}{*}{$\operatorname{RSD}(\%)$} & \multirow{2}{*}{$\begin{array}{c}\text { Egg yolk } \\
\text { Tested value } \\
(\mathrm{mg} / \mathrm{g})\end{array}$} & \\
\hline & & & & & & & RSD (\%) & $\begin{array}{c}\text { Tested value } \\
(\mathrm{mg} / \mathrm{g})\end{array}$ & $\operatorname{RSD}(\%)$ \\
\hline \multirow{10}{*}{$\begin{array}{c}\text { Egg } \\
\text { powder }\end{array}$} & S-1 & $13.34 \pm 0.65$ & 2.87 & $3.23 \pm 0.15$ & 2.55 & $13.72 \pm 0.31$ & 2.26 & $3.38 \pm 0.07$ & 2.01 \\
\hline & $\mathrm{S}-2$ & $13.63 \pm 0.45$ & 1.45 & $3.23 \pm 0.22$ & 2.12 & $13.67 \pm 0.27$ & 1.94 & $3.41 \pm 0.10$ & 3.06 \\
\hline & $\mathrm{S}-3$ & $14.66 \pm 0.17$ & 2.53 & $3.37 \pm 0.23$ & 2.67 & $14.28 \pm 0.12$ & 0.85 & $3.49 \pm 0.06$ & 1.60 \\
\hline & $\mathrm{S}-4$ & $14.75 \pm 0.36$ & 1.87 & $3.18 \pm 0.23$ & 1.46 & $15.03 \pm 0.22$ & 2.64 & $3.28 \pm 0.09$ & 2.10 \\
\hline & $\mathrm{S}-5$ & $14.86 \pm 0.63$ & 1.55 & $3.21 \pm 0.13$ & 3.32 & $14.33 \pm 0.32$ & 2.43 & $3.23 \pm 0.18$ & 1.22 \\
\hline & S-6 & $14.34 \pm 0.73$ & 1.28 & $3.35 \pm 0.12$ & 1.58 & $14.22 \pm 0.15$ & 1.64 & $3.19 \pm 0.15$ & 1.62 \\
\hline & $\mathrm{S}-7$ & $13.33 \pm 0.63$ & 2.12 & $3.12 \pm 0.19$ & 2.96 & $13.74 \pm 0.18$ & 1.26 & $3.05 \pm 0.23$ & 2.22 \\
\hline & S-8 & $12.98 \pm 0.54$ & 3.16 & $3.22 \pm 0.20$ & 1.45 & $13.26 \pm 0.28$ & 1.46 & $3.11 \pm 0.26$ & 0.82 \\
\hline & S-9 & $14.13 \pm 0.38$ & 3.32 & $3.16 \pm 0.21$ & 2.27 & $13.66 \pm 0.30$ & 1.63 & $3.25 \pm 0.23$ & 1.32 \\
\hline & S-10 & $12.88 \pm 0.27$ & 2.42 & $3.12 \pm 0.23$ & 1.65 & $12.59 \pm 0.24$ & 1.55 & $2.94 \pm 0.16$ & 1.24 \\
\hline
\end{tabular}

1) Values are mean \pm S.D of 3 replicates.

$8.50-10.40 \mathrm{mg} / \mathrm{g}$ in egg yolk and the USA as the range of $378-423 \mathrm{mg} / 100 \mathrm{~g}$ in whole egg (no data for egg yolk weight), respectively (Guardiola et al., 1984; Naviglio et al., 2012; Taber et al., 2011). This method is expected to reduce the sample preparation time and material usage compared to existing methods; moreover, industries and certified analysis institutions can use this method to monitor many samples simultaneously.

\section{Conclusions}

A rapid sample preparation method for cholesterol content was applied to egg and egg powder. The accuracy, precision, and recovery of this method were satisfactory. This method can be used as an accurate tool for determining cholesterol levels in eggs and egg powder. Furthermore, the sample preparation time was dramatically redu- ced compared to previously described methods. We found that the cholesterol contents in eggs and egg powder available in Korean markets were similar or lower than other countrie's values known been published. This method is useful for rapid monitoring of the cholesterol content in egg and egg powder as a food ingredient and for precise nutrition labeling of processed food products.

\section{Acknowledgements}

This paper was supported by Konkuk University in 2013.

\section{References}

1. AOAC International. (2002a) AOAC Guidelines for Single Laboratory Validation of Chemical Methods for Dietary Supplements and Botanicals. Association of Official Analytical 
Chemists, Gaithersburg, MD, (USA).

2. AOAC International. (2002b) Appendix D: Guidelines for Collaborative Study Procedures To Validate Characteristics of a Method Analysis. Association of Official Analytical Chemists, Gaithersburg, MD, (USA).

3. Beyer, R. S. and Jensen, L. S. (1989) Overestimation of the cholesterol content of eggs. J. Agric. Food Chem. 37, 917-920.

4. Guardiola, F., Codony, R., Rafecas, M., and Boatella, J. (1994) Selective Gas Chromatographic Determination of Cholesterol in Eggs. J. Am. Oil Chem. Soc. 71, 867-871.

5. Horwitz, W. (2011a) Official Methods of Analysis of AOAC International, 18th ed, Rev 4. In: AOAC Official Method 976. 26, Cholesterol in Multicomponent Foods. Association of Official Analytical Chemists, Gaithersburg, MD (USA), 90-92.

6. Horwitz, W. (2011b) Official Methods of Analysis of AOAC International, 18th ed, Rev 4. In: AOAC Official Method 994. 10, Cholesterol in Foods. Association of Official Analytical Chemists, Gaithersburg, MD (USA), 105-106.

7. Hurst, W. J., Aleo, M. D., and Martin Jr, R. A. (1985) HPLC determination of the cholesterol content of egg noodles as an indicator of egg solids. J. Agric. Food Chem. 33, 820-822.

8. IDF International Dairy Federation. (2001) International Standard ISO 14156IDF 172, Milk and Milk products - Extraction methods for lipids and liposoluble compounds. ISO and IDF, BRU (Belgium).

9. IDF International Dairy Federation. (2006) International Standard ISO 18252IDF 200, Anhydrous milk fat - Determination of sterol composition by gas liquid chromatography (Routine method). ISO and IDF, BRU (Belgium).

10.Jeong, I. S., Kwak, B. M., Ahn, J. H., Leem, D. G., Yoon, T. H., Yoon, C. Y., Jeong, J. Y., Park, J. M., and Kim, J. M. (2012). A novel sample preparation method using rapid nonheated saponification method for the determination of cholesterol in emulsified foods. J. Food Sci. 77, C1042-C1046.

11.Kang, M. H. (2009) Food values. The Korean Nutrition Society, Seoul (Korea), 578-579.

12. Kim, J. M., Park, J. M., Yoon, T. H, Leem, D. G., Yoon, C. Y., Jeong, J. Y., Jeong, I. S., Kwak, B. M., and Ahn, J. H. (2011) Development of analysis method for cholesterol in infant formula by direct saponification. Korean J. Food Sci. An. 6, 944951.

13. Korea Food Code 2012. (2012) 10.1.1.5.5) Cholesterol, 4952.

14. Naviglio, D., Gallo, M., Grottaglie, L., Scala, C., Ferrara, L., and Santini, A. (2012) Determination of cholesterol in Italian chicken eggs. Food Chem. 132, 701-708.

15. Sweeney, J. P. and WeBirauch, J. L. (1976) Summary of available data for cholesterol in foods and methods for its determination. CRC Crit Rev. Food Sci. Nutr. 8, 131-159.

16. Taber, D. F., Li, R., and Anson, C. M. (2011) Isolation of Cholesterol from an Egg Yolk. J. Chem. Eeduc. 88, 1580-1581.

17. United States Department of Agriculture. (2011) USDA National Nutrient Database for Standard Reference, Release 24. USDA Agricultural Research Service, Beltsville, MD, (USA).

$\overline{\text { (Received 2013.3.24/Revised 2013.9.9/Accepted 2013.10.11) }}$ 